\title{
Effect of altitudinal gradients on forest structure and composition on ridge tops in Garhwal Himalaya
}

\author{
C. M. Sharma ${ }^{1}$ Ashish K. Mishra ${ }^{1,2}$ - O. P. Tiwari $^{1} \cdot \operatorname{Ram}_{\text {Krishan }}{ }^{1}$. \\ Y. S. Rana ${ }^{1}$ \\ ${ }^{1}$ Department of Botany, H.N.B. Garhwal University, Garhwal Srinagar, Uttarakhand 246174, India \\ ${ }^{2}$ Department of Environmental Science, Babasaheb Bhimrao Ambedakar University, Lucknow, UP, India
}

Received: 1 July 2016/Revised: 20 May 2017/Accepted: 7 July 2017/Published online: 17 July 2017

(c) Joint Center on Global Change and Earth System Science of the University of Maryland and Beijing Normal University and Springer-Verlag GmbH Germany 2017

\begin{abstract}
Ridge top ecosystems (RTEs) are considered to be more sensitive to global warming as they are characterized by uniform sunlight exposure and low human interferences and hence are perfect places for monitoring and comparing the effects of climate change in species composition. The present study was carried out on RTEs of four different mountain ranges, viz. (1) NarendranagarHindolakhal (2) Mussoorie-Dhanolti (3) ChaurangikhalHarunta and (4) Dayara-Gidara, along altitudinal gradient (situated below 2000 to above $3500 \mathrm{~m}$ ), in Garhwal Himalaya to understand the variation in tree composition and distribution range. 0.1 ha-sized sample plot was used to analyze the tree species, whereas $5 \mathrm{~m} \times 5 \mathrm{~m}$ for saplings and $1 \mathrm{~m} \times 1 \mathrm{~m}$ for seedlings. The tree layers on RTEs were consisted of total 69 tree species, belonging to 55 genera and 39 families. Shorea robusta, Pinus roxburghii, Rhododendron arboreum, Quercus leucotrichophora, Q. floribunda, Q. semecarpifolia, Cedrus deodara, Pinus wallichiana and Abies spectabilis were found as the dominant and well-occupied tree species on the RTEs from lower to higher elevations. The mean stand density was recorded as $597 \pm 29$ trees ha ${ }^{-1}$ (ranged between 546 and 616 trees ha ${ }^{-1}$ ) with a mean basal cover of $77.25 \pm 17.90 \mathrm{~m}^{2} \mathrm{ha}^{-1}$ (ranged between 54.43 and $102.83 \mathrm{~m}^{2} \mathrm{ha}^{-1}$ ). A traditional pattern for tree diversity was recorded which decreased with increasing altitude. The detrended correspondence analysis ordination plot clumped the species together which shared the same habitat and
\end{abstract}

C. M. Sharma and Ashish K. Mishra have contributed equally to this work.

Ashish K. Mishra

ashishmishramlg@gmail.com environmental conditions which revealed that elevation and geographic location were the dominant factors for regional differences in species composition among RTEs.

Keywords Climate change - Ecological indicators · Forest composition - Ridge top ecosystems - Detrended correspondence analysis

\section{Introduction}

The ridge top ecosystems (RTEs) are considered to be more sensitive to global warming as they are characterized by uniform sunlight exposure and low human interferences and hence are perfect places for monitoring and comparing the effects of climate change and predicting the future changes in species composition. In Himalayan region, elevation and climatic factors are the governing factors for regional differences in species composition (Lee and Chun 2016; Sharma et al. 2016). Furthermore, it is supposed that in the event of a rise in temperature at lower elevations the movement/migration of vegetation would be toward upper elevational (Chen and Hill 2011). The recent global warming has resulted in disturbances of ecological relationships, alteration in plant life history and general upward shift in the species distributional ranges (Jurasinski and Kreyling 2007; Pauli et al. 2012). Climate controls the distribution of vegetation (Sharma et al. 2016), and thus, future changes in climate are projected to cause changes in the vegetation distribution ranges. Several studies have attributed widespread changes in plant growth or mortality to climate change, but these efforts have focused on general trends within a biome rather than identifying spatially 
coherent distribution pattern (Pauli et al. 2007; Engler et al. 2009).

The composition and ecosystem services of Himalayan forests depend on forest structure, which is believed to be changing over time. Gottfried et al. (2012) reported ample evidences that ongoing climate change continuously affects the Himalayan Vegetation along with its different components. Rapid geo-climatic variations at different altitudes in Himalaya generate diverse vegetation structure and high species diversity (Chawla et al. 2008). Intensity of major threats to forest ecosystems and biodiversity along altitudinal gradient is directly measured by compositional changes in forest structure. Role of habitat loss due to fragmentation, overexploitation, invasion by alien species and global climate change is premier in disruption of community structure along the altitudinal gradient, which can be used to assess the status of forest composition and alert for future changes. Lots of work have been done on the effects of elevational gradients on forest structure and composition (Sharma et al. 2010; Gairola et al. 2012; Rawat and Chandra 2014), but the studies on change in species composition on RTEs along the altitudinal gradient in Himalaya are completely lacking.

In the western Himalayan region, along lowest and highest elevational transects the changes in forest composition are evident, but they are required to be measured properly (Chitale et al. 2014; Sharma et al. 2014). Projecting future changes in species composition and distribution of vegetation on RTEs at different altitudes is a crucial step toward planning and mitigating the impacts of climate change on biodiversity. The aim of the study is to describe and analyze the forest structure, composition and distribution pattern along elevational gradients, in order to explain the changes in forest composition and characters of forests on RTEs in response to changing climate.

\section{Methodology}

\subsection{Study area}

The study was conducted in four different mountain ranges, viz. (1) Narendranagar-Hindolakhal (<2000 m) (2) Mussoorie-Dhanolti (1900-2900 m) (3) Chaurangikhal-Harunta (2400-3300 m) and (4) Dayara-Gidara (2500-3750 m), of Garhwal Himalaya to assess tree species composition and distribution on different RTEs along the elevational gradient (Above sea level). For this purpose, we selected the RTEs from lower to higher elevations in aforesaid different mountain ranges. In these ranges, the selected RTEs were studied on five different elevations, viz. (a) $<2000 \mathrm{~m}$ (b) $2000-2500 \mathrm{~m}$ (c) $2500-3000 \mathrm{~m}$ (d) 3000-3500 and (e) $>3500 \mathrm{~m}$. The study areas were situated in the catchment of river Ganges (called Bhagirathi toward upstream). Details of study area, forest types and dominant tree species within the selected elevations are shown in Table 1 and Fig. 1.

All the mountain ranges were characterized by undulating topography with gentle slopes on northern, northeastern and northwestern faces and somewhat steep slopes on southern and southwestern directions. Ridges are continuous elevated top made by chain of mountains (Fig. 2). Numerous high ridges, deep gorges and precipitous cliffs, rocky crates and narrow valleys were part of the topography in all the ranges. Geologically, the rocks were complex mixture of mainly sedimentary, low-grade metamorphosed rocks with sequences capped by crystalline nappe (Valdiya 1980).

\subsection{Vegetation composition}

The patterns of forest structure over RTEs were assessed along the elevational gradient in the selected four mountain ranges. The results of all the ranges were compared with one another. Various RTEs along with several plant communities provided an excellent base to investigate the climatic control on plant distribution. The sample plots were laid out from lower to higher elevations, climbing through subtropical, temperate to subalpine forests.

The forest composition was analyzed by laying out a total of 30 sample plots of 0.1 ha each, and three vegetation layers (trees, saplings and seedlings) were studied for knowing the species richness, density, diversity and regeneration status of various forest-forming species as per (Kent and Coker 1992). The trees $(\geq 10 \mathrm{~cm} \mathrm{dbh})$ were analyzed by 0.1 ha-sized sample plots, whereas saplings by ten $5 \mathrm{~m} \times 5 \mathrm{~m}$-sized quadrats and seedling by five $1 \mathrm{~m} \times 1 \mathrm{~m}$-sized quadrats, which were randomly laid out within a 0.1 ha sample plots on each site. Circumference at breast height $(\mathrm{cbh}=1.37 \mathrm{~m})$ was taken for the determination of tree basal area, and in case of saplings and seedlings, it was taken at collar height and finally was calculated as $\pi r^{2}$ (where $r$ is the radius). The data were quantitatively analyzed for density, frequency and abundance, following Curtis and McIntosh (1950). Density and total basal cover values were converted to per hectare $\left(\mathrm{ha}^{-1}\right)$ for extrapolation of the results. Basal cover $\left(\mathrm{m}^{2} \mathrm{ha}^{-1}\right)$ was used to determine the relative dominance of a tree species. Importance value index (IVI) was the sum of relative frequency, relative density and relative dominance (Phillips 1959) of a species. Shannon-Weaver index $(\overline{\mathrm{H}})$ (Cootam and Curtis 1956), Simpson's dominance index (C) (Simpson 1949) and Hill diversity numbers N0, N1 and N2 (Hill 1973) were computed. With the help of CANOCO 5 and SPSS-20 softwares, the results were correlated with temperature, elevation and local climatic conditions to predict the future changes in the vegetation at RTEs. 
Table 1 List of dominant woody plant species in different life phase at different altitudes

\begin{tabular}{llll}
\hline Altitude & Studied area & Dominant forest type & Dominant tree species \\
\hline$<2000$ & Hindolakhal, Mussoorie, Chaurangikhal & Tropical moist & S. robusta, Q. leucotrichophora, T. chebula \\
$2000-2500$ & Mussoorie, Dayara-Gidara, Chaurangikhal & Moist temperate & R. arboretum, Q. floribunda, Q. leucotrichophora \\
$2500-3000$ & Mussoorie, Dayara-Gidara, Chaurangikhal & Moist temperate & Q. floribunda, Q. semecarpifolia, A. pindrow \\
$3000-3500$ & Dayara-Gidara, Chaurangikhal & Moist temperate & A. spectabilis, Q. semecarpifolia, B. utilis \\
$>3500$ & Dayara-Gidara & Subalpine & Q. semecarpifolia, A. spectabilis, B utilis \\
\hline
\end{tabular}

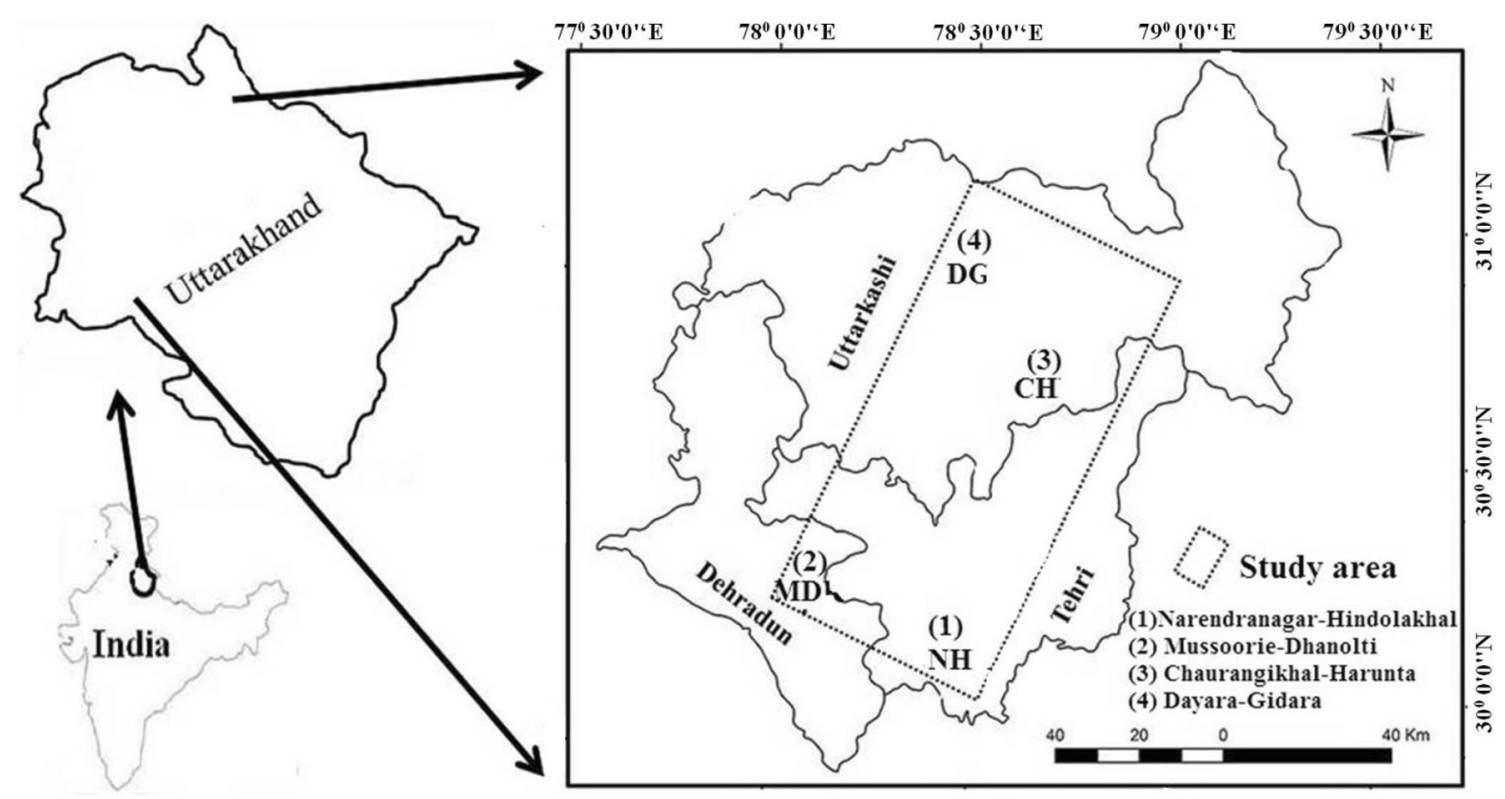

Fig. 1 Map representing the study area

\section{Results}

\subsection{Altitudinal variation in species composition}

The structure and composition of the tree species on various RTEs and elevations are presented in Table 1. Shorea robusta, Pinus roxburghii, Rhododendron arboreum, Cedrus deodara, Quercus semecarpifolia, Q. floribunda, Q. leucotrichophora, Pinus wallichiana and Abies spectabilis were the dominant tree species on RTEs at various elevations (Table 2). The tree layers on all RTEs were consisted of 69 species, represented by 55 genera and 39 families in the study area. Pinaceae and Fabaceae were the dominant families represented by 6 tree species each. Mean stand (stem) density was observed as $597 \pm 29$ trees $\mathrm{ha}^{-1}$, which ranged between 546 and 616 trees ha ${ }^{-1}$ with a total basal cover (TBC) of $77.25 \pm 17.90 \mathrm{~m}^{2} \mathrm{ha}^{-1}$ (ranging from 54.43 to $102.83 \mathrm{~m}^{2} \mathrm{ha}^{-1}$ ) on various ridge top forests. Biodiversity index showed lowest Simpson index value $(0.07)$ on $<2000 \mathrm{~m}$ and highest $(0.44)$ on $>3500 \mathrm{~m}$.
The RTEs of lower altitudes $(<2000 \mathrm{~m}$.) were highly diverse as compared to other altitudes and therefore showed highest value (1.3). The details of forest composition in terms of species frequency, density, basal cover and importance value index on different ridge top forests of all five altitudinal ranges are given in Table 2.

\subsection{DBH Class distribution}

Overall diameter class density, species richness and basal cover distribution on different elevational ranges represented different patterns, i.e., reverse J-shaped, interrupted J-shaped and bell-shaped. Based on the overall basal cover distribution, on RTEs above $3500 \mathrm{~m}$ elevation, an established forest was recorded (this may be because of least disturbance in the inaccessible areas), followed by $3000-3500 \mathrm{~m}$ elevation range, where mature forests were prevalent; however, on RTEs situated below $2000 \mathrm{~m}$ elevation, younger regenerating forests were recorded (probably because of their situation near 

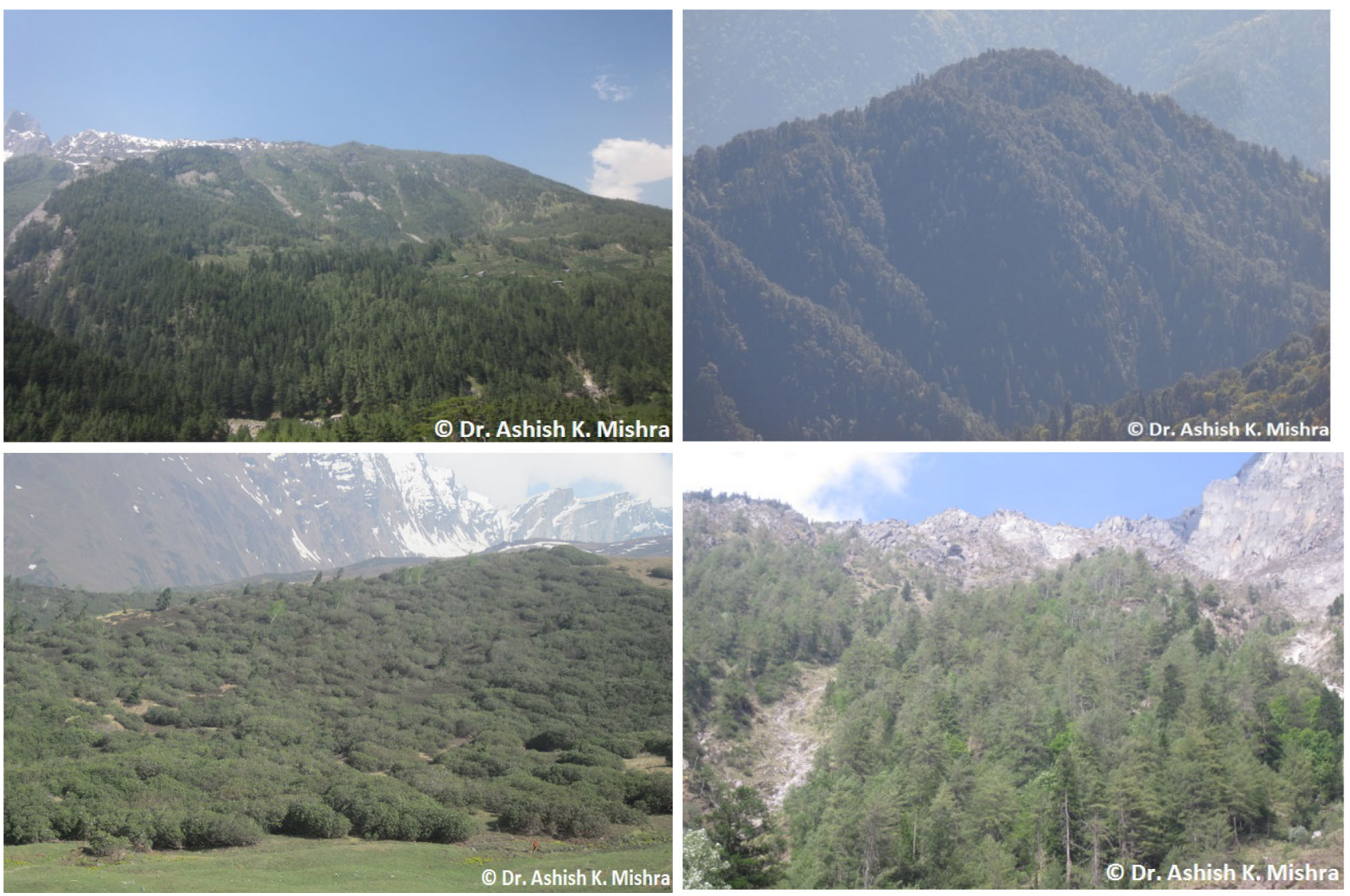

Fig. 2 Ridge tops of study area

Table 2 Tree species composition along the different elevational ranges

\begin{tabular}{llllll}
\hline Altitude & $<2000$ & $2000-2500$ & $2500-3000$ & $3000-3500$ & $>3500$ \\
\hline Species richness & 46 & 20 & 24 & 13 & 3 \\
Genus & 40 & 18 & 19 & 12 & 3 \\
Family & 27 & 12 & 14 & 8 & 3 \\
Stem density $\left(\mathrm{ha}^{-1}\right)$ & 546 & 615 & 600 & 616 & 610 \\
Total basal cover $\left(\mathrm{m}^{2} \mathrm{ha}^{-1}\right)$ & 54.43 & 70.11 & 74.62 & 84.25 & 102.83 \\
Simpson index & 0.07 & 0.12 & 0.13 & 0.20 & 0.44 \\
Shannon-Wiener index & 1.29 & 1.05 & 1.01 & 0.81 & 0.39 \\
Species evenness & 0.78 & 0.81 & 0.73 & 0.73 & 0.82 \\
Hill diversity & & & & & \\
$\mathrm{H}_{0}$ & 46 & 20 & 24 & 13 & 3 \\
$\mathrm{H}_{1}$ & 1.07 & 1.13 & 1.14 & 1.22 & 1.55 \\
$\mathrm{H}_{2}$ & 0.77 & 0.95 & 0.99 & 1.24 & 2.54 \\
\hline
\end{tabular}

habitation zone). The tree density and species richness under different size classes showed a reverse J-shaped pattern in all five altitudinal ranges, whereas above $3500 \mathrm{~m}$ elevational range dbh density pattern was bellshaped (normal distribution). The dbh class-based basal cover data also followed the bell-shaped curve at highest altitude (Fig. 3a, b, c).

\subsection{Species composition and distribution pattern along the elevational gradients}

Detrended correspondence analysis clearly showed that vegetation distribution and association with the RTEs of various mountain ranges were highly similar to each other (Fig. 4). Among five different elevational ranges, the 




Fig. 3 Forest composition by DBH classes (cm) at different altitudes $(\mathrm{m})$; a species richness, b stem density and $\mathbf{c}$ total basal cover $\left(\mathrm{m}^{2}\right.$ $\mathrm{ha}^{-1}$ ) distribution of vegetation was recorded on four different axes which represented four major groups. Forest distribution on $<2000$ m RTE was highly dissimilar to other altitudes. DCA diagram has shown that vegetation structure between 2500 and $3500 \mathrm{~m}$ was almost similar (Fig. 4). The frequency distribution pattern of 34 species is given in Fig. 5. Order of widely distributed species among all ranges was $C$. deodara $(1450-3252 \mathrm{~m})>R$. arboreum $(1732-3474 \mathrm{~m})>$ L. ovalifolia $(1732-3474 \mathrm{~m})>Q$. semecarpifolia $(2320-3540 \mathrm{~m})$ $>$ P. wallichiana (2072-3252 m) $>Q$. leucotrichophora (428-2592 m) $>$ P. smithiana (2072-3125) etc. Linear regression analysis between the components of forest composition and elevational gradients is also shown in Fig. 6.

\section{Discussion}

Plant species may respond to global warming either by adapting their life cycles to the new conditions or by migrating upwards from their conventional distribution
Fig. 4 Detrended correspondence analysis to assess species composition and similarity in vegetation along different altitudes

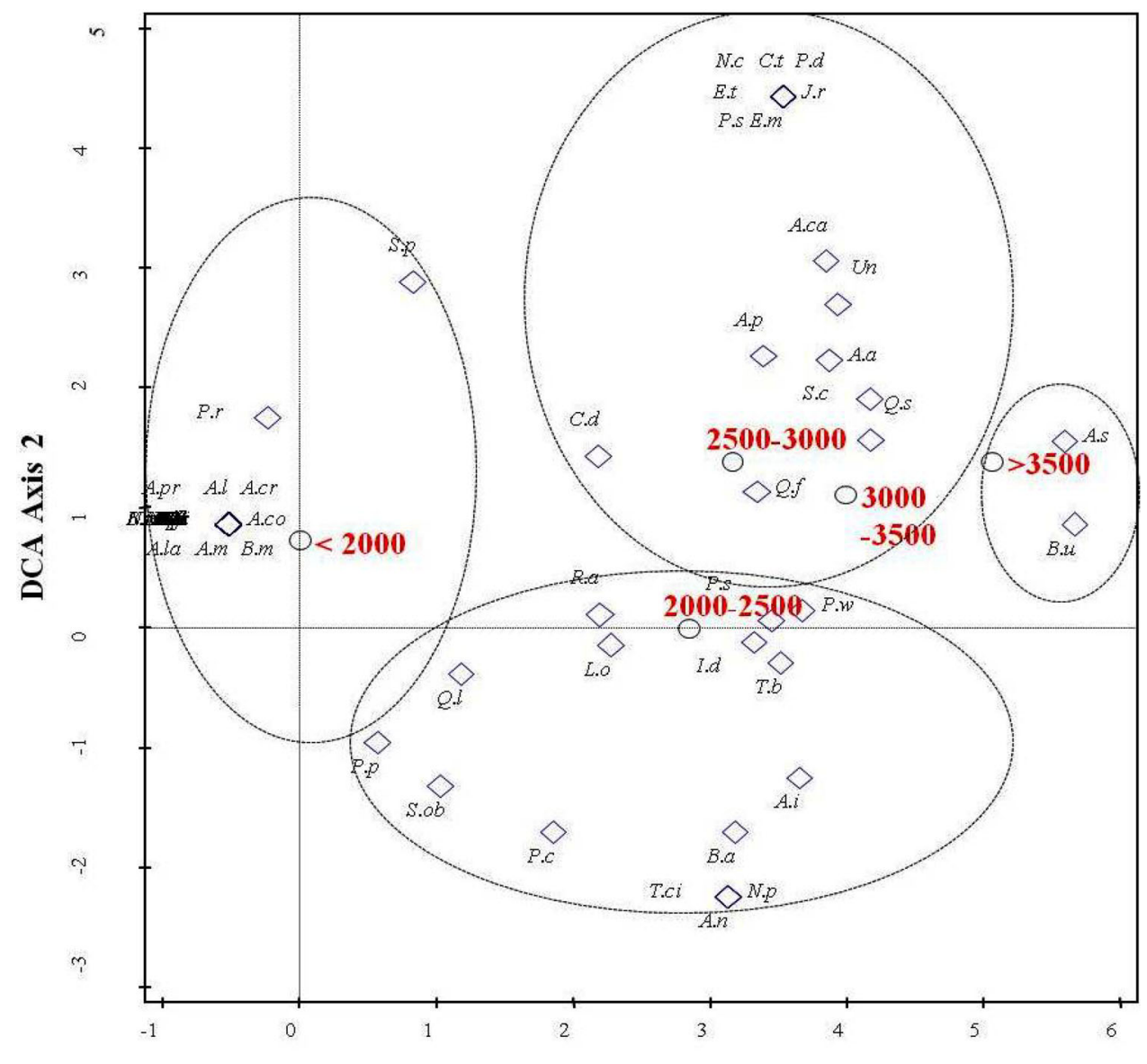

DCAAxis 1 




Fig. 5 Distributional range of dominant woody plant species along the altitudes

ranges to more suitable habitats (Bellard et al. 2012). The study revealed that tree species found in this part of Himalaya exhibited a pattern of distribution along different altitudinal and climatic gradients (Subedi et al. 2015). Tree species richness was observed to be highest (47 species) below $2000 \mathrm{~m}$ elevational zone, followed by $2500-3000 \mathrm{~m}$ (26) and 3000-3500 m (20) and lowest (3 species) above $3500 \mathrm{~m}$. More than two-third of plant species were encountered at the elevation range below $2000 \mathrm{~m}$, where the temperature range was found fluctuating between 8 and $37^{\circ} \mathrm{C}$. Similar results of species richness were reported by Burns (1995) and Austin et al. (1996) in their elevational gradients study. The total species richness was greatest at lower elevation (warmer sites) as compared to the higher elevation (cooler sites).

Assessment of biodiversity and their drivers along environmental gradients is one of the central topics in ecology (Lee and Chun 2016). The variation in quantitative parameters, species richness as well as forest composition among all studied RTEs may be due to difference in climatic, physiographic and edaphic factors. Distributional ranges of several species were reported as segregated along the widened elevational ranges (Kharkwal et al. 2005). Pauses and Austin (2001) suggested that over any large area, the distribution of species richness is likely to be governed by two or more environmental factors. Trends of species richness on RTEs of this study were almost similar to other elevational gradient studies, because the decline in species richness with increasing elevation is widely accepted (Rahbek 1995; Sharma et al. 2016).

The mean stand density on various RTEs was recorded as $597 \pm 29$ stems ha $^{-1}$ (which ranged between 546 and 616 stems $\mathrm{ha}^{-1}$ ) and mean value of TBC as $77.25 \pm 17.9 \mathrm{~m}^{2} \mathrm{ha}^{-1}$ (which ranged from 54.4 to $\left.102.83 \mathrm{~m}^{2} \mathrm{ha}^{-1}\right)$. However, there was a gradual increase in density with an increase in elevation, which is in conformity with the studies performed in the Western Ghats by Parthasarathy and Karthikeyan (1997) and in Himalayan temperate forests by Samant et al. (2002). The recorded density values of this study did not vary considerably from values reported by other authors (Adhikari and Tiwari 1991; Singhal and Soni 1989; Ilorkar and Khatri 2003). From Garhwal Himalaya, Pande (2001) had reported a stem density of 792-1111 stems $\mathrm{ha}^{-1}$, which is higher than our values, whereas the reported TBC range $\left(56-126 \mathrm{~m}^{2} \mathrm{ha}^{-1}\right)$ was similar to our study. All the results on vegetation composition were in accordance with the earlier reported findings by various ecologists for moist Himalayan temperate forests (Singh and Kaushal 2006; Sharma et al. 2009, 2014, 2015).

Forest dominance increased with an increase in the elevation. Simpson's index value was 0.07 below $2000 \mathrm{~m}$, which gradually increased and reached finally up to 0.44 for the forest vegetation above $3500 \mathrm{~m}$. This was due to tolerance-based dominance of only few tree species under severe environmental conditions. Shannon-Weiner's index values ranged from 0.39 to 1.3 and decreased with 


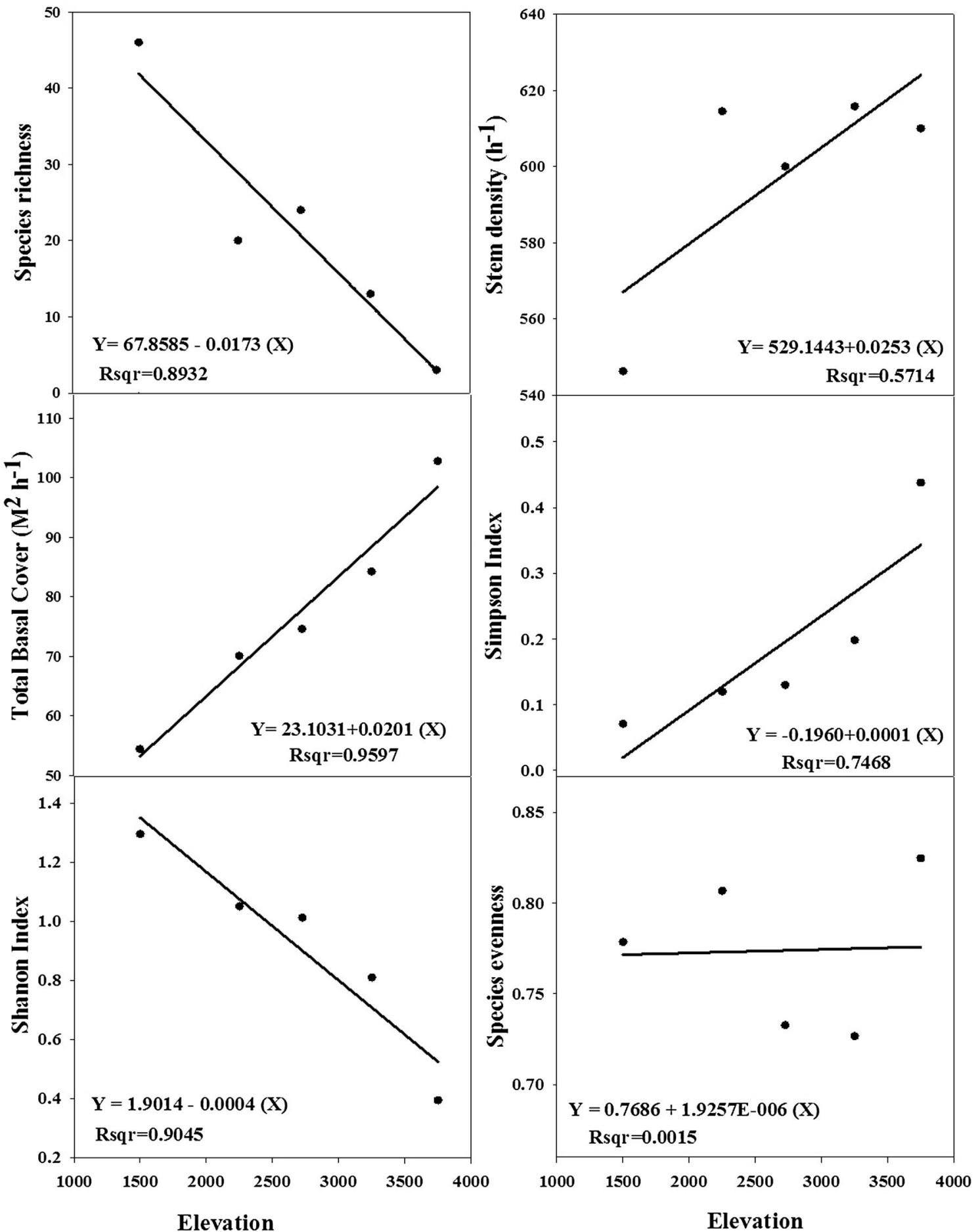

Fig. 6 Linear regression analysis between forest composition and elevation

increasing altitudes/elevations, which was in accordance with the values reported for other temperate forests (Singh and Kaushal 2006; Sharma et al. 2009). The high importance value index (IVI) of species between 600 and $1100 \mathrm{~m}$ indicated their dominance and ecological success, good power of regeneration and ecological amplitude. Similar observations were also recorded by Singh et al. (1991), Gogate and Kumar (1993) and Ilorkar and Khatri (2003).

The DCA revealed that elevation and geographic location were the dominant factors underlying regional 


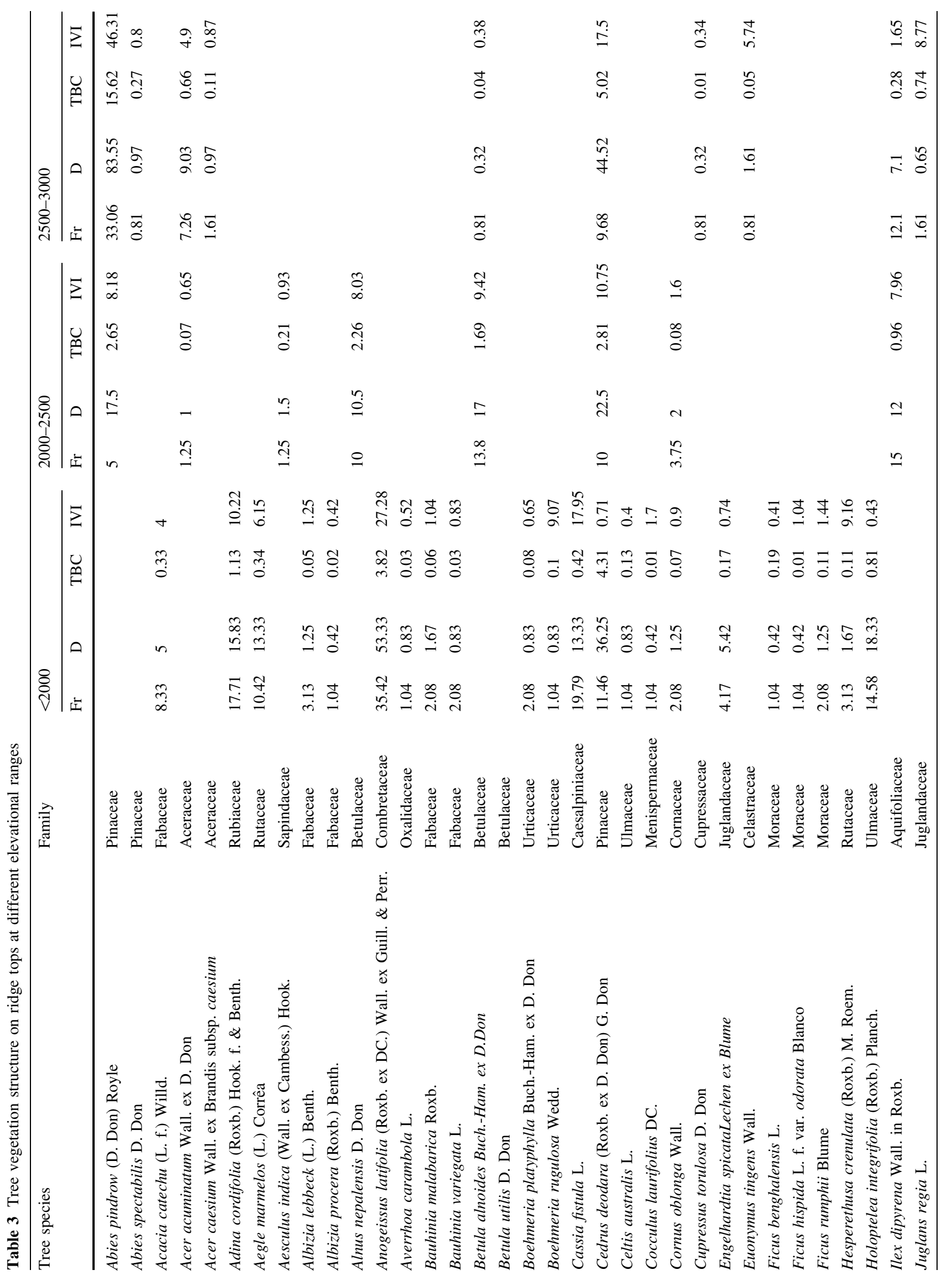









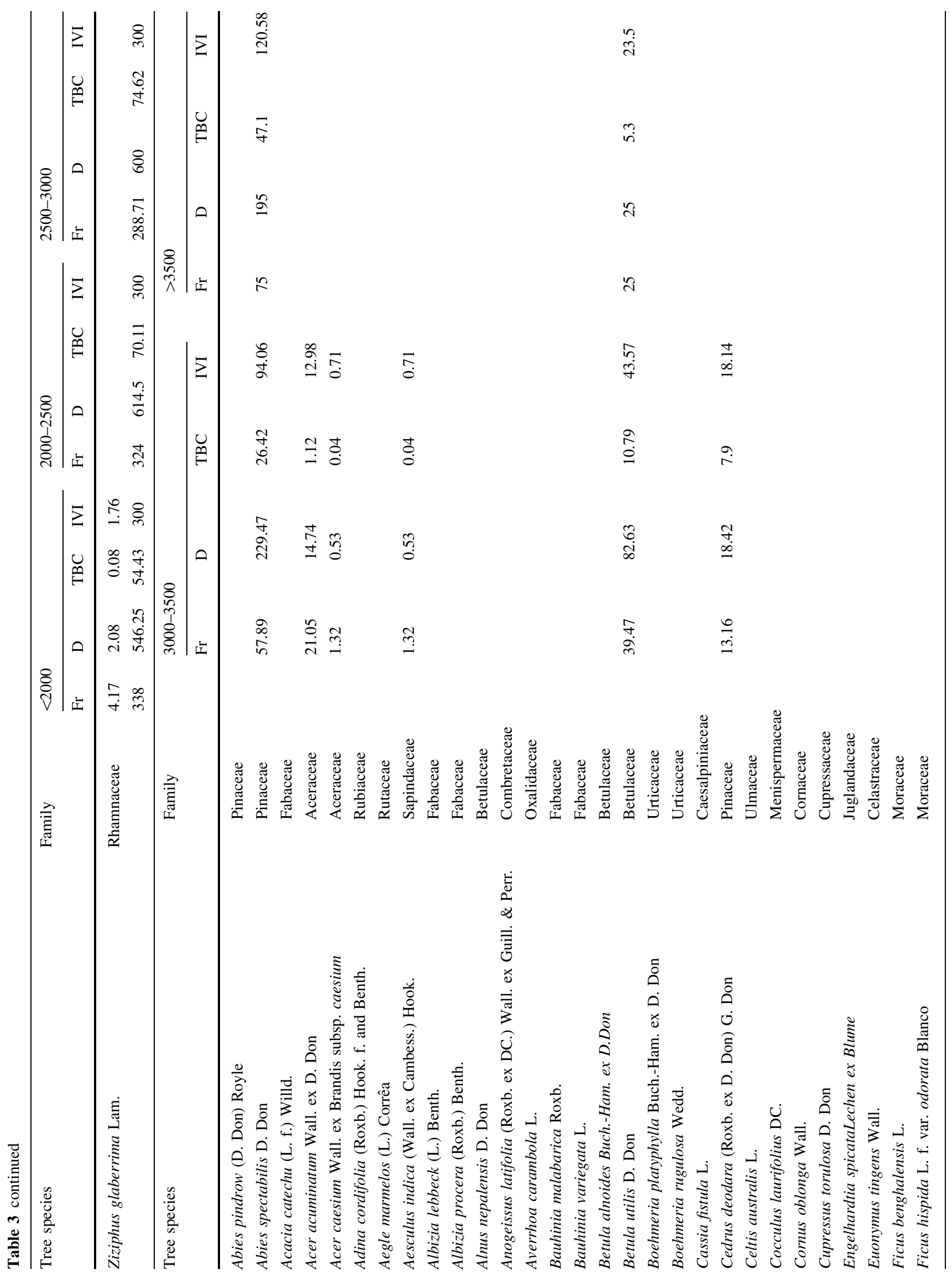




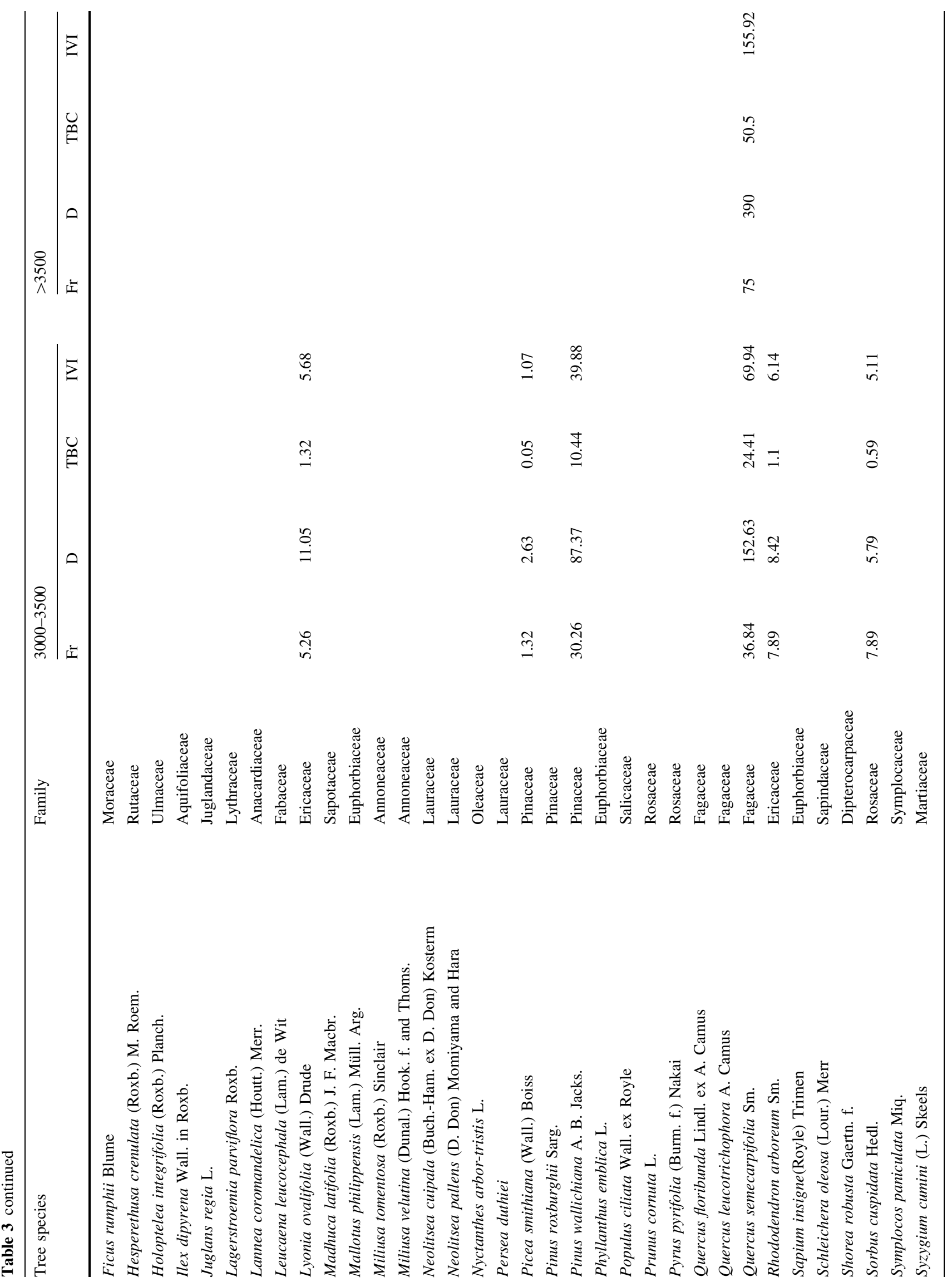




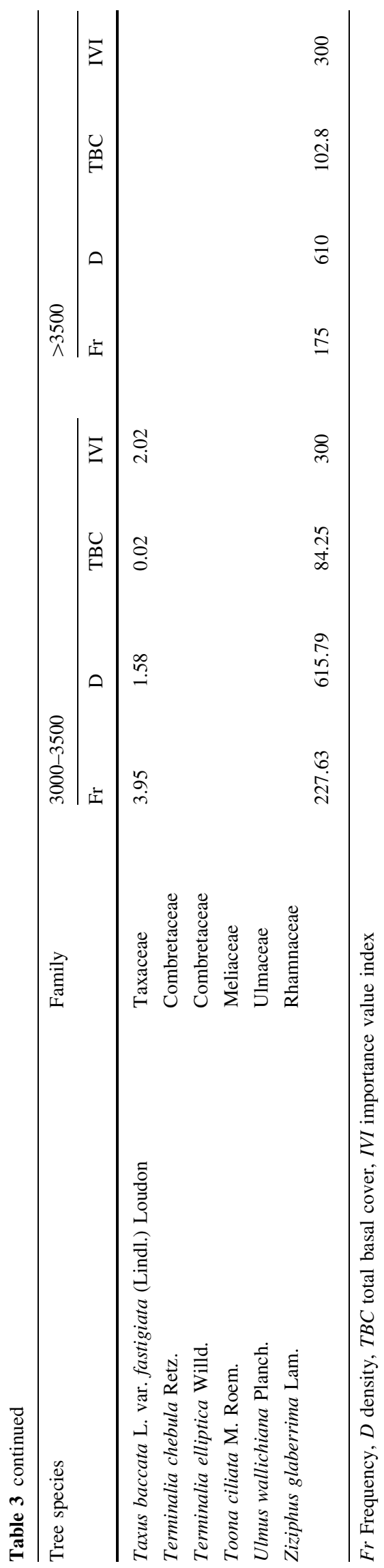

differences in the species composition among sites. DCA clearly showed that vegetation distribution and association with the RTEs of various mountain ranges were focused along the first two DCA axes. RTEs at higher elevations were highly similar in species composition, whereas the vegetation of lower elevation was dissimilar to higher elevation. Mountain topography can influence temperature differences over very short vertical distances (Scherrer and Körner 2010). Elevation itself represents a complex combination of related climatic variables closely correlated with numerous other environmental properties, i.e, soil texture, nutrients and substrate stability (Ramsay and Oxley 1997). Within one elevation, the cofactors such as topography, aspect, inclination of slope and soil types further affect the forest composition (Holland and Steyn 1975). Zhuang et al. (2012) and Moeslund et al. (2013) suggested that differential distribution of solar radiation might produce differences in microclimate (e.g., temperature) and water balance (moisture), which results in growth of different plant communities. Our DCA study shows that aforesaid factors may cause major differences in vegetation composition at different elevations, but these do not affect the higher elevational RTs where almost similar composition and diversity status were observed (Table 3 ).

Distributional pattern of species showed that at lower elevation, the dominance of subtropical S. robusta was affected by Anogeissus latifolia, whereas in temperate region, the $P$. roxburghii forests were found replacing the Quercus spp. (from broadleaf and mixed broadleaf forests) gradually. At the middle elevations, however, the coniferous species such as C. deodara and Cupressus torulosa were also predominantly replacing the broadleaf forests. In subalpine forests, birch (Betula utilis) and fir (A. spectabilis) forests along with some broadleaf species, viz. $R$. arboreum, $Q$. semecarpifolia, etc., have revealed the dominance. The B. utilis, A. spectabilis and $R$. arboreum were also found encroaching the lower alpine meadows through species migration (Sharma et al. 2014). Species distribution along altitudinal gradient was directly controlled by ecophysiological processes of temperature tolerance (Körner 2003). Species from warmer lower elevational vegetation belts took advantage of the improved growing conditions to extend their leading edges to the temperate and subalpine belts at the expense of coldadapted species already occurring there. Linear regression was used to assess the effect of elevational gradient in the species composition on ridge tops. Species richness and tree species diversity were negatively correlated with elevational gradient and decreased with increasing elevation. The occurrence of higher diversity and species richness on lower elevational RTs might thus be explained by the invasion susceptibility of the communities with ample available gaps in sparse vegetation due to anthropogenic 
disturbances, mainly structured by facilitative interactions (Choler et al. 2001). The homogeneous forest was recorded at higher altitudes which emphasized the dominance of single/few species with increasing altitude (as was revealed by Simpson's index). The Shannon-Wiener index showed higher diversity on the RTEs of lower altitudes and lower diversity on the RTEs of higher altitudes.

\section{Conclusion}

The present study highlights the lower elevational RTEs had comparatively higher number of species, whereas lower numbers of species were recorded at higher elevational RTEs, which imply the climatic adaptation by plant species. The findings of this study will provide the baseline data to assess future migration of species. Vegetation response to recent climatic changes on the RTEs is dependent on initial species composition, vegetation structure and environmental conditions. Study results of species distribution will directly reveal the future species shift in Himalayan region and thus will be helpful for planning management and conservation of biodiversity in Himalaya.

Acknowledgements The authors are thankful to the Department of Science and Technology, Government ofIndia, New Delhi, India for providing financial support (Project No. SERB/SR/SO/PS/14/2010).

\section{References}

Adhikari RS, Tiwari A (1991) Microbial decomposition of oak leaf litter in temperate forest of Kumaun Himalayas. Acta Bot Indica 19:195-200

Austin MP, Pausas JG, Nicholls AO (1996) Patterns of tree species richness in relation to environment in southeastern New South Wales, Australia. Austral J Ecol 21:154-164

Bellard C, Bertelsmeier C, Leadley P, Thuiller W, Courchamp F (2012) Impacts of climate change on the future of biodiversity. Ecol Lett 15(4):365-377

Burns BR (1995) Environmental correlates of species richness at Waipoua Forest Sanctuary, New Zealand. N Z J Ecol 19:153-162

Chawla A, Rajkumar S, Singh KN, Lal B, Singh RD, Thukral AK (2008) Plant species diversity along an altitudinal gradient of Bhabha Valley in western Himalaya. J Mt Sci 5(2):157-177

Chen C, Hill JK, ROhlemüller R, Roy DB, Thomas CD (2011) Rapid Range Shifts of Species Associated with High Levels of Climate Warming. Science 333:1024-1026

Chitale VS, Behera MD, Roy PS (2014) Future of endemic flora of biodiversity hotspots in India. PLoS ONE 9(12):52-64

Choler P, Michalet R, Callaway RM (2001) Facilitation and competition on gradients in alpine plant communities. Ecology 82:3295-3308

Cootam G, Curtis JT (1956) The use of distance measures in phytosociology sampling. Ecology 37:451-460

Curtis JT, McIntosh RP (1950) The interrelations of certain analytic and synthetic phytosociological characters. Ecology 31:434-455

Engler R, Randin CF, Vittoz P, Czaka T, Beniston M, Zimmermann NE, Guisan A (2009) Predicting future distributions of mountain plants under climate change: does dispersal capacity matter? Ecography 32:34-45

Gairola S, Sharma CM, Ghildiyal SK, Suyal S (2012) Regeneration dynamics of dominant tree species along an altitudinal gradient in moist temperate valley slopes of the Garhwal Himalaya. J For Res 23:53-63

Gogate MG, Kumar A (1993) An ecological audit of teak plantations in west Chandrapur Project Division. Ind For 119:265-294

Gottfried M, Pauli H, Futschik A, Akhalkatsi M (2012) Continentwide response of mountain vegetation to climate change. Nat Clim Change 2:111-115

Hill MO (1973) Diversity and evenness: a unifying notation and its consequences. Ecology 54:427-432

Holland PG, Steyn DG (1975) Vegetational responses to latitudinal variations in slope angle and aspect. J Biogeo 2:179-183

Ilorkar VM, Khatri PK (2003) Phytosociological study of Navegaon National Park (Maharashtra). Ind For 129:377-387

Jurasinski G, Kreyling J (2007) Upward shift of alpine plants increases floristic similarity 263 of mountain summits. J Veg Sci 18:711-718

Kent M, Coker P (1992) Vegetation description and analysis. A practical approach. CRC Belhaven Press, London, pp 10-27

Kharkwal G, Mehrotra P, Rawat YS, Pangtey YPS (2005) Phytodiversity and growth form in relation to altitudinal gradient in the Central Himalayan (Kumaun) region of India. Curr Sci $89: 873-878$

Körner C (2003) Alpine plant life: functional plant ecology of high mountain ecosystems, 2nd edn. Springer, Berlin

Lee CB, Chun JH (2016) Environmental drivers of patterns of plant diversity along a wide environmental gradient in Korean temperate forests chang. Forest 7:19. doi:10.3390/f7010019

Moeslund JE, Arge L, Bøcher PK (2013) Topography as a driver of local terrestrial vascular plant diversity patterns. Nordic J Bot 31:129-144

Pande PK (2001) Quantitative vegetation analysis as per aspect and altitude, and regeneration behaviour of tree species in Garhwal Himalayan forest. Ann For 9:39-52

Parthasarathy N, Karthikeyan R (1997) Biodiversity and population density of woody species in a tropical evergreen forest in Courtallum reserve forest, Western Ghats, India. Trop Ecol 38:297-306

Pauli H, Gottfried M, Reiter K, Klettner C, Grabherr G (2007) Signals of range expansions and contraction of vascular plants in the high Alps: observation (1994-2004) at GLORIA master site Schrankogel, Tyrol, Austria. Glob Change Biol 13:147-156

Pauli H, Gottfried M, Dullinger S, Abdaladze O, Akhalkatsi M, Benito Alonso JL (2012) Recent plant diversity changes on Europe's mountain summits. Science 336:353-355

Pauses JG, Austin MK (2001) Patterns of plant species richness in relation to different 290 environments: an appraisal. J Veg Sci 12:153-166

Phillips J (1959) Agriculture and ecology in Africa, p 424

Rahbek C (1995) The elevation al gradient of species richness: a uniform pattern? Ecography 18:200-205

Ramsay PM, Oxley ERB (1997) The growth form composition of plants communities in Ecuadorian Paramos. Plant Ecol 131:173-192

Rawat VS, Chandra J (2014) Vegetational diversity analysis across different habitats in Garhwal Himalaya. J Bot. doi:10.1155/2014/ 538242

Samant SS, Joshi HC, Arya SC, Pant S (2002) Studies on the structure, composition and changes of the vegetation in Nanda Devi Biosphere Reserve of West Himalaya-Final Technical Report Submitted to Ministry of Environment and Forests, New Delhi, India 
Scherrer D, Körner C (2010) Infra-red thermometry of alpine landscapes challenges climatic warming projections. Glob Change Biol 16:2602-2613

Sharma CM, Suyal S, Gairola S, Ghildiyal SK (2009) Species richness and diversity along an altitudinal gradient in moist temperate forest of Garhwal Himalaya. J Am Sci 5:119-128

Sharma CM, Suyal S, Ghildiyal SK, Gairola S (2010) Role of physiographic factors in distribution of Abies pindrow (Silver Fir) along an altitudinal gradient in Himalayan temperate Forests. Environ 30:76-84

Sharma CM, Mishra AK, Prakash O, Dimri S, Baluni P (2014) Assessment of forest structure and woody plant regeneration on ridge tops at upper Bhagirathi basin in Garhwal Himalaya. Trop Plant Res 1:62-71

Sharma CM, Mishra AK, Krishan R, Tiwari OP, Rana YS (2015) Variation in vegetation composition, biomass production and carbon storage in ridge top forests of high mountains of Garhwal Himalaya. J Sustain For. doi:10.1080/10549811.20151118387

Sharma CM, Mishra AK, Krishan R, Tiwari OP, Rana YS (2016) Impact of climate on structure and composition of Ridge Top forests in Garhwal Himalaya. Taiwan 61(2):61-69
Simpson EH (1949) Measurement of diversity. Nature 163:688

Singh Y, Kaushal A (2006) Extraction of geomorphological features using radarsat 318 Data. J Indian Soc Remote 34:300-307

Singh JS, Singh KP, Agrawal M (1991) Environmental degradation of the Obra-Renukoot-Singrauli area, India, and its impact on natural and derived ecosystems. Environ 11:171-180

Singhal RM, Soni S (1989) Quantitative ecological analysis of some woody species of Mussoorie Himalayas (UP). Ind For 115:327-337

Subedi SC, Bhattarai KR, Chauudhary RP (2015) Distribution pattern of vascular plant species of mountains in Nepal and their fate against global warming. J Mt Sci 12:1345

Valdiya KS (1980) Geology of kumaun lesser Himalaya. Wadia Institute of Himalayan Geology, Dehradun, p 221

Zhuang L, Tian ZP, Chen YN (2012) Community characteristics of wild fruit forests along elevation gradients and the relationships between the wild fruit forests and environments in the Keguqin Mountain region of Iii. J Mt Sci 9:115-126 